Discussion Paper No. 14-039

\title{
Industry Structure and Pricing Over the Business Cycle
}

Yossi Spiegel and Konrad Stahl

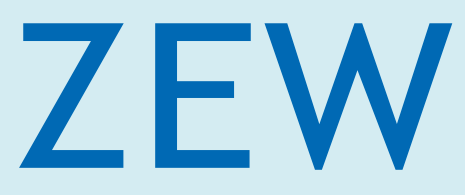

Zentrum für Europäische Wirtschaftsforschung GmbH Centre for European Economic Research 
Discussion Paper No. 14-039

\title{
Industry Structure and Pricing Over the Business Cycle
}

\author{
Yossi Spiegel and Konrad Stahl
}

Download this ZEW Discussion Paper from our ftp server:

http://ftp.zew.de/pub/zew-docs/dp/dp14039.pdf

Die Discussion Papers dienen einer möglichst schnellen Verbreitung von neueren Forschungsarbeiten des ZEW. Die Beiträge liegen in alleiniger Verantwortung der Autoren und stellen nicht notwendigerweise die Meinung des ZEW dar.

Discussion Papers are intended to make results of ZEW research promptly available to other economists in order to encourage discussion and suggestions for revisions. The authors are solely responsible for the contents which do not necessarily represent the opinion of the ZEW. 


\title{
Industry structure and pricing over the business cycle
}

\author{
Yossi Spiegel $^{*}$ and Konrad Stahl ${ }^{\dagger}$
}

June 11, 2014

\begin{abstract}
We consider the interaction between an incumbent firm and a potential entrant, and examine how this interaction is affected by demand fluctuations. Our model gives rise to procyclical entry, prices, and price-cost margins, although the average price in the market can be countercyclical if the entrant is a first mover, and capacity utilization can be either pro- or countercyclical if the incumbent is a first mover. Moreover, our results show that entry deterrence by the incumbent firm can either amplify or dampen the effect of demand fluctuations on prices, price-cost margins, and capacity utilization.
\end{abstract}

JEL Classification: D43, L41

Keywords: price competition, business cycle, entry, entry deterrence

*Recanati Business School, Tel Aviv University, CEPR, and ZEW; email: spiegel@post.tau.ac.il, http://www.tau.ac.il/ ${ }^{\text {sppiegel }}$

${ }^{\dagger}$ Universität Mannheim, CEPR, CESifo and ZEW; email: kos@econ.uni-mannheim.de, http://www.vwl.unimannheim.de/stahl 


\section{Introduction}

The pricing behavior of firms over the business cycle has been the subject of an ongoing debate among economists. In particular, there is a debate on whether price-cost margins and profitability are pro- or countercyclical. One reason why economists pay attention to the proor countercyclicality of price-cost margins and profitability is because they can either amplify or dampen the effects of other business cycle shocks. For instance, high price-cost margins in recessions keep prices from falling and hence may slow down the recovery process. Likewise, low price-cost margins in booms keep prices low and hence boost demand and may extend the boom. Moreover, understanding how market structure and prices respond to external shocks is one of the core issues in Industrial Organization.

There is an extensive empirical literature on the cyclical behavior of prices and price-cost margins. The evidence in this literature is mixed. Domowitz, Hubbard, and Peterson (1986a, 1986b, 1987, 1988) find that price-cost margins in U.S. manufacturing industries are procyclical in concentrated industries, but tend to be countercyclical in relatively unconcentrated industries. Price-cost margins are especially procyclical in intermediate goods industries, in non-durable goods industries, in capital intensive industries, and in low price-cost margin industries. Haskel, Martin and Small (1995) obtain similar results for UK manufacturing industries.

Other authors, however, find strong evidence for countercyclical price-cost margins, including Bils (1987) and Rotemberg and Woodford (1991) for U.S. data, Portier (1995) for French data, and Oliveira Martins, Scarpetta, and Pilat (1996) for 14 OECD countries. ${ }^{1}$ More recently, Nekarda and Ramey (2013) have revisited the methodology used by, among others, Bils (1987) and Rotemberg and Woodford (1999). Using updated empirical methods and updated U.S. data, they show that prices over marginal costs are procyclical, conditional on technology shocks, and

\footnotetext{
${ }^{1}$ Oliveira Martins, Scarpetta, and Pilat find that price-cost margins are especially countercyclical in concentrated industries. They attribute this finding to "increased competition during economic booms" which is "likely to be more apparent for the industries characterised by the dominance of large firms with market power."
} 
either procyclical or acyclical, conditional on demand shocks. These results hold both when they use quarterly aggregate data on the U.S. private economy, as well as when they use annual four-digit manufacturing data.

A possible reason why the empirical evidence is inconclusive is that entry and exit, and therefore the structure of the industry, are also affected by business cycles. This suggests that in order to fully understand how prices and price-cost margins vary over the business cycle, one need to study the joint determination of industry structure and pricing. In this paper we develop a simple theoretical model intended to examine the nexus between prices and entry in response to demand shocks. To this end, we consider two firms which produce a homogenous product and compete by setting prices. The two firms face a step demand function; the quantity demanded and the willingness of consumers to pay are both larger in booms than in recessions. The two firms differ in two respects. First, firm 1 is an incumbent, while firm 2 is a potential entrant and needs to incur an avoidable fixed cost in order to enter the market. Second, firm 1 has a larger capacity than firm 2. We consider both the timing where firm 1 is the first mover, as well as the opposite timing where firm 2 is the first mover. ${ }^{2}$

In spite of its simplicity, our model yields predictions on the cyclical behavior of prices, price-cost margins, output levels, profitability, entry, and capacity utilization. In particular, we find that entry, prices, and price-cost margins are all procyclical, regardless of which firm is the first mover. By contrast, the average price in the market can be countercyclical if firm 2 is the first mover and firm 1's capacity utilization can be either pro- or countercyclical when firm 1 is the first mover. Moreover, our analysis shows that prices, price-cost margins, and capacity utilization can be more or less volatile than the demand function. This implies that entry deterrence by the incumbent firm can either amplify or dampen the effect of demand fluctuations on these variables.

\footnotetext{
${ }^{2}$ When the two firms move simultaneously, our model is essentially a Bertrand duopoly with capacity constraints and hence it does not admit an equilibrium in pure strategies. We leave the characterization of the resulting mixed strategy equilibrium for future research.
} 
The theoretical literature on the cyclicality of prices and price-cost margins can be roughly divided into four classes of models. First, price-cost margins will be cyclical if either prices or marginal costs are rigid. For instance, if prices are sticky while marginal costs vary procyclically, then price-cost margins are countercyclical. This explanation, however, also implies that profits should be countercyclical, which is at odds with empirical evidence (see e.g., Rotemberg and Woodford, 1999). By contrast, if marginal costs are rigid while prices are procyclical, then price-cost margins will also tend to be procyclical. ${ }^{3}$

Second, several authors argue that price-cost margins are countercyclical because the elasticity of demand is higher in booms than in recessions; the inverse elasticity rule then implies that price-cost margins should be lower in booms. Warner and Barsky (1995) argue that demand is more elastic in booms because each consumer wishes to buy more units in high demand states (e.g., holidays and weekends) and hence price reductions in these states generate more sales. In Bils (1989) and in Klemperer (1995), a firm faces a mix of repeat and new customers. The latter have a lower willingness to pay. ${ }^{4}$ In booms, there are more new customers who respond to low prices, so demand is more elastic than in recessions. Edmond and Veldkamp (2009) argue that demand is more elastic in booms because consumers' income, and hence buyers' willingness to pay, are less dispersed than in recessions. As a result, price reductions in booms attract more consumers. In all of these models, however, strategic interaction among firms, which is the main driving force in our model, do not play a role.

Third, some authors like Gottfries (1991) and Chevalier and Scharfstein (1996), develop models in which price-cost margins can be countercyclical due to capital market imperfections. Firms face a tradeoff between raising prices and boosting their short-run profits, and keeping prices low in order to build long-run market share. In Gottfries (1991), cash flows during

\footnotetext{
${ }^{3}$ For instance, Domowitz, Hubbard, and Peterson (1986b) argue that, due to a large degree of unionization in concentrated industries, real wages, which are a main contributor to costs, tend to be rigid.

${ }^{4}$ In Bils (1989), the good is an experience good. New customers have a lower willingness to pay because they are still unsure about the good's quality. In Klemperer (1995) the lower willingness to pay is due to the fact that new customers need to pay a switching cost when they adopt the firm's product for the first time.
} 
recessions are low relative to liabilities, so firms give more weight to their short-run goals and set high prices. By contrast, in booms, firms can meet their financial obligations, and hence they give more weight to long-term goals which justify low prices. In Chevalier and Scharfstein (1996), firms favor short-term goals during recessions because their low cash flow during recessions mean that they face a risk of bankruptcy; this creates a debt overhang problem, which makes firms more short-term oriented. They provide empirical support for their model using data from the U.S. supermarket industry.

Our model belongs to the fourth class of models, in which the cyclicality of price-cost margins is due to strategic interaction among firms. Green and Porter (1984) consider an infinitely repeated oligopoly model in which firms are subject to unobserved demand shocks. When sales are low, firms are unsure whether this is due to low demand or to deviation by a rival firm from a collusive arrangement. To sustain collusion, firms start periodic price wars when demand is low and hence the equilibrium features high collusive prices in booms and low competitive prices in recessions.

By contrast, Rotemberg and Saloner (1986) consider an infinitely repeated oligopoly model with publicly observable i.i.d. demand shocks. During booms, when demand is high, firms are more tempted to deviate from collusion and steal market share. Hence, the collusive price must adjust downward to eliminate the incentive of firms to deviate. ${ }^{5}$ Haltiwanger and Harrington (1991) consider a model with deterministic demand fluctuations. They define booms as periods in which demand is increasing and recessions as periods in which demand is decreasing. Since the future gain from collusion is lower when demand is decreasing, collusive prices must decrease to eliminate the incentive of firms to deviate. Hence, for the same level of demand, the

\footnotetext{
${ }^{5}$ Staiger and Wolak (1992) consider a related model in which firms must determine their capacities at the start of each period before demand shocks are realized. They show that collusion tends to break down in periods of low demand when firms have excess capacity. Ellison (1994) assesses the applicability of the Green and Porter (1984) and Rotemberg and Saloner (1986) models, using data from the "Joint Executive Committee" railroad cartel from the late 19th century. His estimates find some support for the predictions of the Green and Porter model.
} 
collusive price is lower during periods of falling demand than during periods of rising demand. ${ }^{6}$ Bagwell and Staiger (1997) consider a model in which demand follows a Markovian structure and identify booms with periods of fast-growing demand and recessions with periods of slowgrowing demand. They show that collusive prices move procyclically when demand growth rates are positively correlated over time and countercyclically when they are negatively correlated over time. $^{7}$

In these models, demand fluctuations affect the ability of firms to collude. In our model by contrast, demand fluctuations affect the incentive of an incumbent firm to either accommodate or deter an entrant. Hence, our model yields results not only on the cyclicality of prices, but also on the cyclicality of entry and capacity utilization. ${ }^{8}$ These results are essentially robust to the whether the incumbent or the entrant are first movers. In addition, when the entrant is the first mover, our model also gives rise to price dispersion and shows that it can be either larger or smaller in booms than in recessions.

\footnotetext{
${ }^{6}$ Fabra (2006) shows that this prediction can be overturned if firms' capacities are sufficiently small. Rosenbaum and Sukharomana (2001) use data from the U.S. Portland cement industry and find support for Haltiwanger and Harrington's predictions that for a given level of demand, the price in the rising part of the cycle is above the price in the falling part of the cycle and that profits reach a peak before market demand.

${ }^{7}$ Galeotti and Schiantarelli (1998) examine data on 19 U.S. industrial sectors over the period 1949-1987 and show that price-cost margins are negatively related to the current state of demand and positively related to expected future demand. This evidence is consistent with Haltiwanger and Harrington (1991) and Bagwell and Staiger (1997).

${ }^{8}$ Portier (1995) also studies the joint detremination of entry and prices in the context of a simple quantity competition model with an incumbent firm, who acts as a Stackelberg leader, and a potential entrant. In the equilibrium of his model, the number of firms is procyclical and the price (there are no marginal costs in his model so the price is also the markup) is countercyclical. Another paper which considers a non-collusive model of competition under demand fluctuations (but with a fixed number of firms) is Reynolds and Wilson (2005). Their model predicts that during a demand expansion, firms charge the short-run competitive price, but in a recession, they set prices above the competitive price. Thus, price markups over the competitive price are countercyclical in their model. Consistent with this prediction, they find evidence from U.S. manufacturing industries that price changes have higher variance in recessions than in booms.
} 
The rest of this paper is organized as follows. In section 2 we describe the model. In Section 3 we characterize the equilibrium under the assumption that firm 1 is the first mover and in Section 4 we consider the opposite situation in which firm 2 is the first mover. Concluding remarks are in Section 5.

\section{The model}

Two price-setting firms produce a homogeneous product and face a step demand function that depends on the state of the economy, which is either a boom (state $b$ ), or a recession (state $r$ ). In booms, consumers wish to buy $Q^{b}$ units and their willingness to pay per unit is $\alpha^{b}$, while in recessions, they wish to buy $Q^{r}$ units and their willingness to pay per unit is $\alpha^{r}$, where $Q^{b}>Q^{r}$ and $\alpha^{b}>\alpha^{r}$. That is, consumers wish to buy more and are willing to pay more in booms than in recessions. Albeit simple, this demand specification allows us to conduct separately two interesting comparisons, namely between the variation in consumers' willingness to pay and equilibrium prices, and between the variation in quantities demanded and capacity utilization.

The two firms differ both in terms of their fixed costs and capacities. Firm 1 is an incumbent that has no fixed cost and has a capacity normalized to 1. Firm 2 is a potential entrant that needs to spend a cost $F$ in order to enter the market with exogenous capacity $k$, where

$$
k<Q^{r}<1<Q^{b}<1+k .
$$

This assumption implies that firm 2 cannot serve the entire market even in recessions, firm 1 can serve the entire market in recessions but not in booms, and together, the two firms can always serve the entire demand.

Both firms produce at constant marginal cost $c$. Hence the average cost of firm 2 when

operating at full capacity $k$, is $A C \equiv c+\frac{F}{k}$. To ensure that firm 2's entry is never blockaded, we assume that $A C<\alpha^{r}$. In addition, to restrict the number of different cases we would need 
to consider, we assume that

$$
F>\left(Q^{b}-1\right)\left(\alpha^{b}-c\right)
$$

This assumption rules out the possibility that in booms, firm 2 will enter the market by charging a price of $\alpha^{b}$, above firm 1's price, and will serve the residual demand, $Q^{b}-1$, left after firm 1 sells up to its capacity. In other words, this assumption means that in order to enter the market profitably, firm 2 must undercut firm 1's price (though as we shall see below, this is possible only when firm 1 's price is sufficiently high).$^{9}$

In what follows, we will characterize the equilibrium under two alternative scenarios: (i) firm 1 sets its price before firm 2 decides whether or not to enter, and if so, at which price; and (ii) firm 2 decides whether or not to enter and at which price before firm 1 sets its own price. In both cases, the two firms know the state of the economy before they make their choices.

Before proceeding, it is worth noting that although we consider a single period model, our results can also be interpreted as the Markov perfect equilibrium of an infinite period model in which demand is i.i.d. across periods and firm 2 needs to incur an avoidable fixed cost whenever it chooses to operate in the market. We leave the more interesting case, where firm 2 needs to incur a fixed cost only when it (re)enters the market after being out (but not if it already operates in the market), for future research. This case is substantially harder because then firm 1 may wish to drive firm 2 out of the market in order to make it costly for firm 2 to reenter, while firm 2 may wish to stay in the market even when it is currently losing money in order to save on the cost of reentering the market later on.

\footnotetext{
${ }^{9}$ We should emphasize that assumption (2) is made for only for convenience. In a more general, but analytically much more involved setting, firm 2 should be allowed to enter at a higher price if consumers' willingness to pay and/or quantity demanded are sufficiently high.
} 


\section{Firm 1 is the first mover}

Let $p_{1}^{i}$ be the price that firm 1 sets in state $i=r, b$, before firm 2 decides whether or not to enter the market. Since the products are homogeneous, it is clear that if firm 2 decides to enter, it will set its price, $p_{2}^{i}$, just below $p_{1}^{i}$, and will sell up to its capacity $k$. Firm 1 will then serve the residual demand, $Q^{i}-k$, at a price $p_{1}^{i}$. If $p_{1}^{i}$ is sufficiently low, then firm 2 decides not to enter because undercutting $p_{1}^{i}$ entails a loss. Although firm 2 could still enter in booms by charging a price above $p_{1}^{b}$ and then serve the residual demand not served by firm $1, Q^{b}-1,{ }^{10}$ its resulting profit would be negative since (2) implies that $\left(Q^{b}-1\right)\left(p_{2}^{b}-c\right)-F \leq\left(Q^{b}-1\right)\left(\alpha^{b}-c\right)-F<0$. Hence, under (2), firm 2 will never enter the market by setting a price above $p_{1}$. If firm 2 decides to stay out, then firm 1 either serves the entire demand in recessions by selling $Q^{r}$, or sells up to its capacity, 1 , in booms. Consequently, the profits of the two firms in state $i=b, r$ are given by

$$
\pi_{1}^{i}=\left\{\begin{array}{cc}
\min \left\{Q^{i}, 1\right\}\left(p_{1}^{i}-c\right) & \text { if firm } 2 \text { stays out } \\
\left(Q^{i}-k\right)\left(p_{1}^{i}-c\right) & \text { if firm } 2 \text { enters }
\end{array}\right.
$$

and

$$
\pi_{2}^{i}=\left\{\begin{array}{cc}
0 & \text { if firm } 2 \text { stays out } \\
k\left(p_{1}^{i}-A C\right) & \text { if firm } 2 \text { enters. }
\end{array}\right.
$$

Firm 1 as the first mover has two options that dominate all others: (i) accommodate firm 2 by setting the maximal price $p_{1}^{i}=\alpha^{i}$; or (ii) deter firm 2's entry by setting a limit price just below firm 2's average cost $A C$, which is a feasible pricing strategy as $A C<\alpha^{r}$. Under option (i), firm 2 will undercut $\alpha^{i}$ slightly and will sell up to its capacity $k$. Firm 1 in turn will serve the residual demand $Q^{i}-k$. The resulting profits of firms 1 and 2 are $\left(Q^{i}-k\right)\left(\alpha^{i}-c\right)$ and $k\left(\alpha^{i}-A C\right)$, respectively. Under option (ii), firm 2 cannot profitably undercut firm 1 , so firm 1 will serve the entire market in a recession and will sell up to its capacity in booms (the demand in booms exceeds firm 1's capacity since $Q^{b}>1$ ). The resulting profit of firm 1 is then $Q^{r}(A C-c)$ in recessions and $A C-c$ in booms. Firm 2 in turn faces no residual demand in

\footnotetext{
${ }^{10}$ In recessions, $Q^{r}<1$, so firm 1 serves the entire market if $p_{1}^{r}<p_{2}^{r}$.
} 
recessions, and due to (2), it cannot make a positive profit in booms by serving the residual demand, $Q^{b}-1$. Hence, firm 2 will stay out of the market whenever $p_{1}^{i}=A C$.

To determine firm 1's equilibrium choice, note that since it can always ensure itself a profit of $\left(Q^{i}-k\right)\left(\alpha^{i}-c\right)$ by serving the residual demand at $\alpha^{i}$, firm 1 will never set a limit price $p_{1}^{i}$ such that

$$
\min \left\{Q^{i}, 1\right\}\left(p_{1}^{i}-c\right) \leq\left(Q^{i}-k\right)\left(\alpha^{i}-c\right)
$$

Hence, the lowest limit prices that firm 1 will ever charge in booms and in recessions, respectively, are

$$
J^{b} \equiv c+\left(Q^{b}-k\right)\left(\alpha^{b}-c\right), \quad J^{r} \equiv c+\left(1-\frac{k}{Q^{r}}\right)\left(\alpha^{r}-c\right) .
$$

Notice that $J^{b}>J^{r}$ since

$$
\left(Q^{b}-k\right)\left(\alpha^{b}-c\right)>(1-k)\left(\alpha^{r}-c\right)>\left(1-\frac{k}{Q^{r}}\right)\left(\alpha^{r}-c\right),
$$

where the first inequality follows because $Q^{b}>1$ and $\alpha^{b}>\alpha^{r}$ and the second inequality follows because $Q^{r}<1$. Recalling that in order to deter entry firm 1 needs to set a price of $A C$ both in booms and in recessions, we have the following result:

Proposition 1: Suppose that firm 1 is the first mover. Then the subgame perfect equilibrium is as follows:

(i) If $A C<J^{r}$, then firm 1 accommodates firm 2 both in booms and in recessions and both firms charge $\alpha^{i}$ in state $i=b, r$. Firm 1 sells $Q^{i}-k$ and firm 2 sells $k$.

(ii) If $J^{r}<A C<J^{b}$, then firm 1 accommodates firm 2 in booms by charging $\alpha^{b}$, but deters firm 2's entry in recessions by charging a limit price $p_{1}^{r}=A C$. When firm 2 enters in booms, it also charges $\alpha^{b}$ and the resulting quantities sold by firms 1 and 2 are $Q^{b}-k$ and $k$, respectively. In recessions, firm 2 stays out of the market and firm 1 sells $Q^{r}$.

(iii) If $A C>J^{b}$, then firm 1 deters firm 2's entry both in booms and in recessions by charging a limit price $p_{1}^{r}=p_{1}^{b}=A C$. Firm 1 sells 1 in booms and $Q^{r}$ in recessions. 
Intuitively, to deter firm 2's entry, firm 1 needs to set a limit price equal to firm 2's average cost. Firm 1, however, is willing to cut its price only to $J^{b}$ in booms and to $J^{r}$ in recessions in order to deter entry. Equation (6) shows that $J^{b}>J^{r}$, implying that firm 1 is more eager to deter entry in recessions. The reason is that firm 1's profit from accommodation is lower in recessions than in booms because firm 1's quantity, as well as its price, are procyclical $\left(Q^{b}-k\right.$ and and $\alpha^{b}$ in booms versus $Q^{r}-k$ and $\alpha^{r}$ in recessions). Although firm 1's quantity under deterrence is also lower in recessions than in booms ( 1 in booms and $Q^{r}$ in recessions), the effect of booms on firm 1's profits under accommodation is larger, so firm 1 is more willing to accommodate entry in booms, and by implication, it is more eager to deter entry in recessions.

Proposition 1 is illustrated in Figure 1 (prices in recessions are in solid lines and prices under booms in broken lines). When $A C<J^{r}$, firm 2 enters the market both in booms and in recessions and both firms charge the monopoly prices $\alpha^{b}$ in booms and $\alpha^{r}$ in recessions. When $J^{r}<A C<J^{b}$, firm 2 enters only in booms and if it does, both firms charge the monopoly price $\alpha^{b}$. In recessions, firm 1 deters entry by charging a limit price $A C$. When $A C>J^{b}$, firm 1 charges a limit price of $A C$ both in booms and in recessions and firm 2 stays out of the market. An interesting implication of the fact that the price is $\alpha^{b}$ or $\alpha^{r}$ when firm 2 is accommodated, but only $A C$ when firm 2 is deterred, is that we get an inverse relationship between prices and concentration: duopoly is associated with relatively high prices, whereas (contested) monopoly is associated with relatively low prices. ${ }^{11}$

As Figure 1 shows, the interesting case arises when $J^{r}<A C<J^{b}$ because then entry occurs in booms, but not in recessions. Consequently, the resulting market structure is statedependent: duopoly with high monopoly prices during booms, and contested monopoly with a low predatory price in recessions.

\footnotetext{
${ }^{11}$ Our assumption that consumers have identical willingness to pay implies that high prices in our model do not entail a deadweight loss. But since firm 2 needs to incur an entry cost, total welfare is higher under (contested) monopoly than under duopoly. Moreover, consumer surplus is higher under monopoly due to the threat of firm 2 's entry into the market.
} 

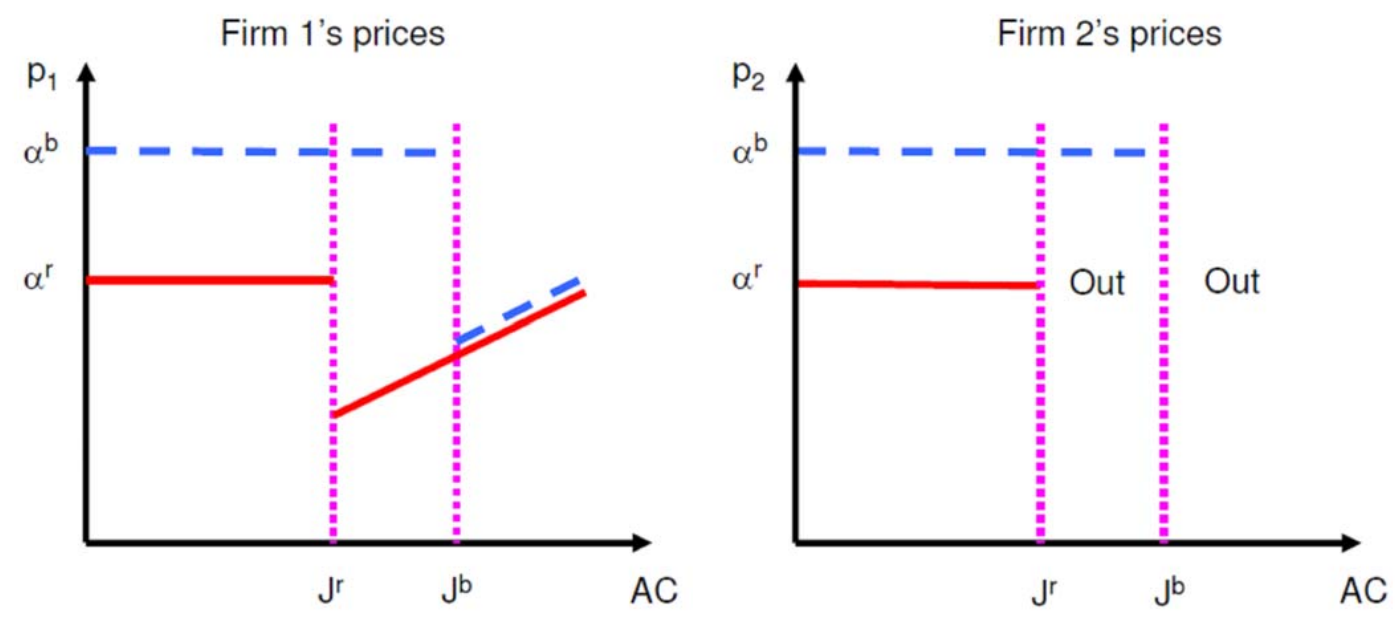

Figure 1: The equilibrium prices when firm 1 is a leader

Proposition 1 yields the following predictions:

Procyclical prices: Prices are higher in booms than in recessions. The only exception arises when $A C>J^{b}$, in which case firm 1's price is equal to $A C$ both in booms and in recessions. The question, however, is whether the equilibrium price variations merely reflect the change in consumers' willingness to pay. It turns out that the strategic interaction between the two firms, and the potentially different industry structure in booms and recessions, has interesting effects on the volatility of equilibrium prices, relative to that of consumers' willingness to pay.

We will measure the volatility of equilibrium prices and consumers' willingness to pay in terms of their respective coefficients of variation, defined as the standard deviation divided by the mean. To compute the coefficient of variation, let $\beta$ denote the probability of a boom and $1-\beta$ the probability of a recession. Then, the expected willingness of Consumers to pay, $W$, is

$$
E(W)=\beta \alpha^{b}+(1-\beta) \alpha^{r},
$$


and its variance over the business cycle is

$$
\begin{aligned}
\operatorname{Var}(W) & =\beta\left(\alpha^{b}-E(W)\right)^{2}+(1-\beta)\left(\alpha^{r}-E(W)\right)^{2} \\
& =\beta(1-\beta)\left(\alpha^{b}-\alpha^{r}\right)^{2} .
\end{aligned}
$$

Now the coefficient of variation of $W$ is

$$
C V(W)=\frac{\sqrt{\operatorname{Var}(W)}}{E(W)}=\frac{\sqrt{\beta(1-\beta)}\left(\alpha^{b}-\alpha^{r}\right)}{E(W)} .
$$

We now compare $C V(W)$ with the coefficient of variation, $C V(p)$, of equilibrium prices. The respective calculations are

$$
E(p)=\left\{\begin{array}{cc}
\beta \alpha^{b}+(1-\beta) \alpha^{r} & A C \leq J^{r}, \\
\beta \alpha^{b}+(1-\beta) A C & J^{r}<A C \leq J^{b} \\
A C & A C>J^{b}
\end{array}\right.
$$

and

$$
\operatorname{Var}(p)=\left\{\begin{array}{cc}
\beta(1-\beta)\left(\alpha^{b}-\alpha^{r}\right)^{2} & A C \leq J^{r}, \\
\beta(1-\beta)\left(\alpha^{b}-A C\right)^{2} & J^{r}<A C \leq J^{b}, \\
0 & A C>J^{b} .
\end{array}\right.
$$

Hence, the coefficient of variation of the equilibrium price is

$$
C V(p)=\left\{\begin{array}{cc}
\frac{\sqrt{\beta(1-\beta)}\left(\alpha^{b}-\alpha^{r}\right)}{\beta \alpha^{b}+\left(1-\beta \alpha^{r}\right.} & A C \leq J^{r}, \\
\frac{\sqrt{\beta(1-\beta)}\left(\alpha^{b}-A C\right)}{\beta \alpha^{b}+(1-\beta) A C} & J^{r}<A C \leq J^{b}, \\
0 & A C>J^{b} .
\end{array}\right.
$$

It is easy to check that $C V(W)=C V(p)$ if $A C \leq J^{r}, C V(W)<C V(p)$ if $J^{r}<A C \leq J^{b}$, and $C V(W)>C V(p)$ if $A C>J^{b}$.

We summarize the results as follows:

Proposition 2: The strategic interaction between the two firms has the following implications for equilibrium price volatility: 
(i) If $A C \leq J^{r}$, equilibrium prices exhibit the same volatility as consumers' willingness to pay.

(ii) If $J^{r}<A C<J^{b}$, equilibrium prices are more volatile than consumers' willingness to pay.

(iii) If $A C>J^{b}$, equilibrium prices are less volatile than consumers' willingness to pay.

Hence, the volatility of consumers' willingness to pay and equilibrium prices is identical only when $A C \leq J^{r}$, in which case firm 2 is accommodated in both booms and recessions. Whenever $J^{r}<A C<J^{b}$, however, the equilibrium prices are more volatile than is the consumers' willingness to pay. That is, the equilibrium price volatility is amplified by firm 1's strategic decision to deter entry in recessions, because while the equilibrium price is equal to the willingness to pay, $\alpha^{b}$, in booms, it is lower than that in recessions, as $A C<\alpha^{r}$. Finally, if $A C>J^{b}$, the volatility of equilibrium prices is zero, and thus obviously smaller than that of consumers' willingness to pay.

No price dispersion: Whenever firm 2 enters the market, the two firms charge the same price so there is no price dispersion within the same period. As we shall see in the next section, this is no longer necessarily true when firm 2 is the first mover.

Procyclical price-cost margins: We specify price-cost margins by the Lerner index. When firm 2 is accommodated, the Lerner index of both firms is $\frac{\alpha^{i}-c}{\alpha^{i}}$. When firm 1 deters firm 2's entry by setting a price $A C$, the Lerner index of firm 1 is $\frac{A C-c}{A C}<\frac{\alpha^{i}-c}{\alpha^{i}}$. Hence, the industry Lerner index in state $i$ is given by

$$
L^{i}=\left\{\begin{array}{cc}
\frac{\alpha^{i}-c}{\alpha^{i}} & A C \leq J^{i}, \\
\frac{A C-c}{A C} & A C>J^{i} .
\end{array}\right.
$$

Since $J^{b}>J^{r}$, it follows that $L^{b} \geq L^{r}$, with strict inequality whenever $J^{r}<A C \leq J^{b}$ (i.e., when the market is duopoly in booms and contested monopoly in recessions). As mentioned in the introduction, the empirical evidence on the cyclicality of price-cost margins is mixed. It 
should be noted that our results are driven by the fact that firm 1 finds it more profitable to charge a low limit price and deter firm 2's entry during recessions. But since we only consider two firms, our predictions apply only to concentrated markets in which entry deterrence is a relevant possibility.

Procyclical entry: To derive predictions about entry, let us assume that $A C$ is drawn from some distribution function $G(A C)$ on the interval $\left[0, \alpha^{r}\right]$, and is observed by both firms before any decisions are taken. Then, Proposition 1 implies that in equilibrium, the probability of entry is $G\left(J^{b}\right)$ in booms, and $G\left(J^{r}\right)$ in recessions, where $G\left(J^{b}\right)>G\left(J^{r}\right)$. This prediction is consistent with Portier (1995) who shows that the number of firms in France is positively correlated with the French GDP during the period 1977-1989. Likewise, Campbell (1998) finds significant positive correlation between the entry rates in the U.S. manufacturing sector and the U.S. GDP during the 1972-1988 period, and Lee and Mukoyama (2013) find that entry rates of U.S. manufacturing plants during the 1972-1997 period are on average significantly higher in booms than in recessions.

Procyclical profits and profit margins: When $A C \leq J^{r}$, firm 1's profit in state $i$ is $\left(Q^{i}-k\right)\left(\alpha^{i}-c\right)$. Since $Q^{b}>Q^{r}$ and $\alpha^{b}>\alpha^{r}$, firm 1's profit is procyclical. Likewise, when $A C>J^{b}$, firm 1's profit in state $i$ is $Q^{i}(A C-c)$, so again it is procyclical. When $J^{r}<A C \leq J^{b}$, firm 1's profit in booms, $\left(Q^{b}-k\right)\left(\alpha^{b}-c\right)$, is also higher than firm 1's profit is recessions, $Q^{r}(A C-c)$, since

$$
\left(Q^{b}-k\right)\left(\alpha^{b}-c\right) \geq Q^{r}\left(Q^{b}-k\right)\left(\alpha^{b}-c\right)=Q^{r}\left(J^{b}-c\right) \geq Q^{r}(A C-c),
$$

where the first inequality arises since $Q^{r} \leq 1$, the equality follows from the definition of $J^{b}$, and the last inequality arises since $A C \leq J^{b}$. Hence firm 1's profit is also procyclical in this range. As for firm 2, its profit when $A C \leq J^{r}$ is $k\left(\alpha^{i}-A C\right)$ which is procyclical since $\alpha^{b}>\alpha^{r}$. When $J^{r}<A C \leq J^{b}$, firm 2 operates in the market and makes a positive profit only in booms; hence its profit is also procyclical in this range. When $A C>J^{b}$, firm 2 is out of the market in both 
states. The procyclicality of profits is well-documented empirically (see e.g., Rotemberg and Woodford, 1999).

Our model also yields predictions regarding profit margins, i.e., profits divided by quantities. The profit margin of firm 1 is $\alpha^{i}-c$ when $A C \leq J^{r}, \alpha^{b}-c$ in booms and $A C-c$ in recessions when $J^{r}<A C \leq J^{b}$, and $A C-c$ in both booms and recessions when $A C>J^{b}$. Firm 2's profit margin is $\alpha^{i}-A C$ when $A C \leq J^{r}, \alpha^{b}-A C$ in booms and 0 in recessions when $J^{r}<A C \leq J^{b}$, and 0 when $A C>J^{b}$. Hence our model predicts that profit margins should be (weakly) procyclical. This result is consistent with Machin and Van Reenen (1993) who study a panel of 709 large UK firms over the 1970s and 1980s and find that firm-level profit margins are strongly procyclical.

Pro- or countercyclical capacity utilization by firm 1: Clearly, if the industry structure (and capacities) would stay unchanged over the business cycle, then capacity utilization would vary procyclically, as firms produce more in booms than in recessions. The question is what happens when the endogenous determination of industry structure is explicitly taken into account. In what follows we study the cyclical behavior of firm 1 which operates in our model for all parameter values.

To address this question, recall that firm 1's capacity is 1 , so firm 1's capacity utilization is equal to firm 1's output. In booms, firm 1 produces $Q^{b}-k$ if $A C<J^{b}$ and 1 if $A C>J^{b}$, so its expected output, and hence its expected capacity utilization, is

$$
C U_{1}^{b}=\left(Q^{b}-k\right) G\left(J^{b}\right)+1-G\left(J^{b}\right)
$$

In recessions, firm 1 produces $Q^{r}-k$ if $A C<J^{r}$ and $Q^{r}$ if $A C>J^{r}$, so its expected capacity utilization is

$$
C U_{1}^{r}=\left(Q^{r}-k\right) G\left(J^{r}\right)+Q^{r}\left(1-G\left(J^{r}\right)\right) .
$$

Since $Q^{b}-k>Q^{r}-k$ and $J^{b}>J^{r}$, then $\left(Q^{b}-k\right) G\left(J^{b}\right)>\left(Q^{r}-k\right) G\left(J^{r}\right)$. At the same time, if $Q^{r}$ is sufficiently close to 1 , then it is also possible that $1-G\left(J^{b}\right)<Q^{r}\left(1-G\left(J^{r}\right)\right)$, so the relationship between $C U_{1}^{b}$ and $C U_{1}^{r}$ is in general ambiguous. 
It is interesting to note that the capacity utilization of firm 1 in state $i$ declines with $J^{i}$, which in turn varies with $\alpha^{i}$. Intuitively, the larger $\alpha^{i}$ is, the more tempting it is for firm 1 to accommodate firm 2, in which case firm 1's capacity utilization is lower than in the case where it deters entry.

As in the case of equilibrium prices, the question now is whether the cyclical behavior of capacity utilization merely reflects the volatility of quantities demanded, or whether it is also affected by the strategic interaction between the two firms. To address this question, note that the expected quantity demanded is

$$
E(Q)=\beta Q^{b}+(1-\beta) Q^{r}
$$

and its variance over the business cycle is

$$
\begin{aligned}
\operatorname{Var}(Q) & =\beta\left(Q^{b}-E(Q)\right)^{2}+(1-\beta)\left(Q^{r}-E(Q)\right)^{2} \\
& =\beta(1-\beta)\left(Q^{b}-Q^{r}\right)^{2}
\end{aligned}
$$

Hence, the coefficient of variation of demand is

$$
C V(Q)=\frac{\sqrt{\operatorname{Var}(Q)}}{E(Q)}=\frac{\sqrt{\beta(1-\beta)}\left(Q^{b}-Q^{r}\right)}{E(Q)} .
$$

We now compare $C V(Q)$ with the coefficient of variation of the capacity utilization of firm 1. Recalling that firm 1's capacity utilization is equal to firm 1's output, and noting from Proposition 1 that firm 1's output is $Q^{b}-k$ if $A C<J^{b}$ and 1 if $A C>J^{b}$ in booms and $Q^{r}-k$ if $A C<J^{r}$ and $Q^{r}$ if $A C>J^{r}$ in recessions, the expected value and variance of firm 1's capacity utilization are given by

$$
E\left(C U_{1}\right)=\left\{\begin{array}{cc}
\beta\left(Q^{b}-k\right)+(1-\beta)\left(Q^{r}-k\right)=E(Q)-k & A C \leq J^{r}, \\
\beta\left(Q^{b}-k\right)+(1-\beta) Q^{r}=E(Q)-\beta k & J^{r}<A C \leq J^{b} \\
\beta+(1-\beta) Q^{r}=E(Q)-\beta\left(Q^{b}-1\right) & A C>J^{b}
\end{array}\right.
$$

and

$$
\operatorname{Var}\left(C U_{1}\right)=\left\{\begin{array}{cc}
\beta(1-\beta)\left(Q^{b}-Q^{r}\right)^{2} & A C \leq J^{r} \\
\beta(1-\beta)\left(Q^{b}-Q^{r}-k\right)^{2} & J^{r}<A C \leq J^{b} \\
\beta(1-\beta)\left(1-Q^{r}\right)^{2} & A C>J^{b}
\end{array}\right.
$$


Hence, the coefficient of variation of firm 1's capacity utilization is

$$
C V\left(C U_{1}\right)=\left\{\begin{array}{cc}
\frac{\sqrt{\beta(1-\beta)}\left(Q^{b}-Q^{r}\right)}{E(Q)-k} & A C \leq J^{r}, \\
\frac{\sqrt{\beta(1-\beta)}\left(Q^{b}-Q^{r}-k\right)}{E(Q)-\beta k} & J^{r}<A C \leq J^{b}, \\
\frac{\sqrt{\beta(1-\beta)}\left(1-Q^{r}\right)}{E(Q)-\beta\left(Q^{b}-1\right)} & A C>J^{b} .
\end{array}\right.
$$

It is now easy to check that $C V\left(C U_{1}\right)>C V(Q)$ if $A C \leq J^{b}$, and $C V\left(C U_{1}\right)<C V(Q)$ if $A C>J^{b}$. We summarize the comparison of $C V\left(C U_{1}\right)$ with $C V(Q)$ in the following result:

Proposition 3: The strategic interaction between the firms has the following implications for the volatility of equilibrium capacity utilization of firm 1:

(i) If $A C \leq J^{b}$, the equilibrium capacity utilization of firm 1 is more volatile than the quantity demanded.

(ii) If $A C>J^{b}$, the equilibrium capacity utilization of firm 1 is less volatile than the quantity demanded.

Proposition 3 shows that the strategic interaction between the two firms either dampens or amplifies the volatility of capacity utilization of the firm 1 which is the incumbent. This result corresponds nicely to Proposition 2: when $A C \leq J^{b}$, i.e., when firm 2's fixed costs is low relative to demand, firm 1 finds it optimal to accommodate firm 2 at least in booms. The equilibrium prices then are (weakly) more volatile than the willingness of consumers to pay, while firm 1's capacity utilization is (strictly) more volatile than the quantity demanded. In the opposite case, where $A C>J^{b}$, firm 1 finds it optimal to deter firm 2's entry both in booms and in recessions, and in this case, the equilibrium price and firm 1's capacity utilization are less volatile than the corresponding demand primitives. 


\section{Firm 2 is the first mover}

We now turn to the alternative scenario in which firm 2 first decides whether or not to enter; and if it does, it sets a price $p_{2}^{i}$ in state $i=b, r$. Firm 1 observes firm 2's entry decision and price and then sets $p_{1}^{i}$. This scenario corresponds to the Judo Economics model of Gelman and Salop (1983), in which the entrant moves before the incumbent responds. In recessions, firm 2 sells a positive quantity only if firm 1 does not undercut it. In booms, firm 2 could also serve the residual demand $Q^{b}-1$ when firm 1 undercuts it, but by equation (2), its profit would be negative: $\left(Q^{b}-1\right)\left(p_{2}^{b}-c\right)-F \leq\left(Q^{b}-1\right)\left(\alpha^{b}-c\right)-F<0$. Hence, firm 2 can profitably enter the market only if it sets a sufficiently low "judo" price, which firm 1 does not wish to undercut. From the previous section it should be clear that the required judo prices are $J^{r}$ in recessions and $J^{b}$ in booms. Obviously, firm 2 is willing to set these prices only if they exceed its average cost $A C$. Hence,

Proposition 4: Suppose that firm 2 is the first mover. Then the subgame perfect equilibrium is as follows:

(i) If $A C<J^{r}$, then firm 2 enters the market in both states and sets $p_{2}^{b}=J^{b}$ in booms and $p_{2}^{r}=J^{r}$ in recessions. Firm 1 in turn sets $p_{1}^{i}=\alpha^{i}$ and sells $Q^{i}-k$, while firm 2 sells $k$.

(ii) If $J^{r}<A C \leq J^{b}$, then firm 2 enters the market only in booms and sets $p_{2}^{b}=J^{b}$. Firm 1 in turn sets $p_{1}^{b}=\alpha^{b}$. Firm 1 sells $Q^{i}-k$, and firm 2 sells $k$. In recessions, firm 2 stays out of the market. Firm 1 sets $p_{1}^{r}=\alpha^{r}$ and sells $Q^{r}$.

(iii) If $A C>J^{b}$, then firm 2 cannot profitably enter the market in either state. Firm 1 then sets $p_{1}^{i}=\alpha^{i}$ and sells $Q^{r}$ in recessions, and 1 in booms.

Proposition 4 shows that the patterns of entry and output levels are exactly as in Proposition 1. Moreover, Figure 2 shows that as in the case where firm 1 is the first mover, the equilibrium prices when firm 2 is the first mover are also procyclical in the sense that they are 
higher in booms than in recessions (the prices in booms are $\alpha^{b}$ and $J^{b}$ and in recessions they are $\alpha^{r}$ and $J^{r}$ ). Hence, the predictions on entry, sales, and the procyclicality of prices are robust to the identity of the leading firm.
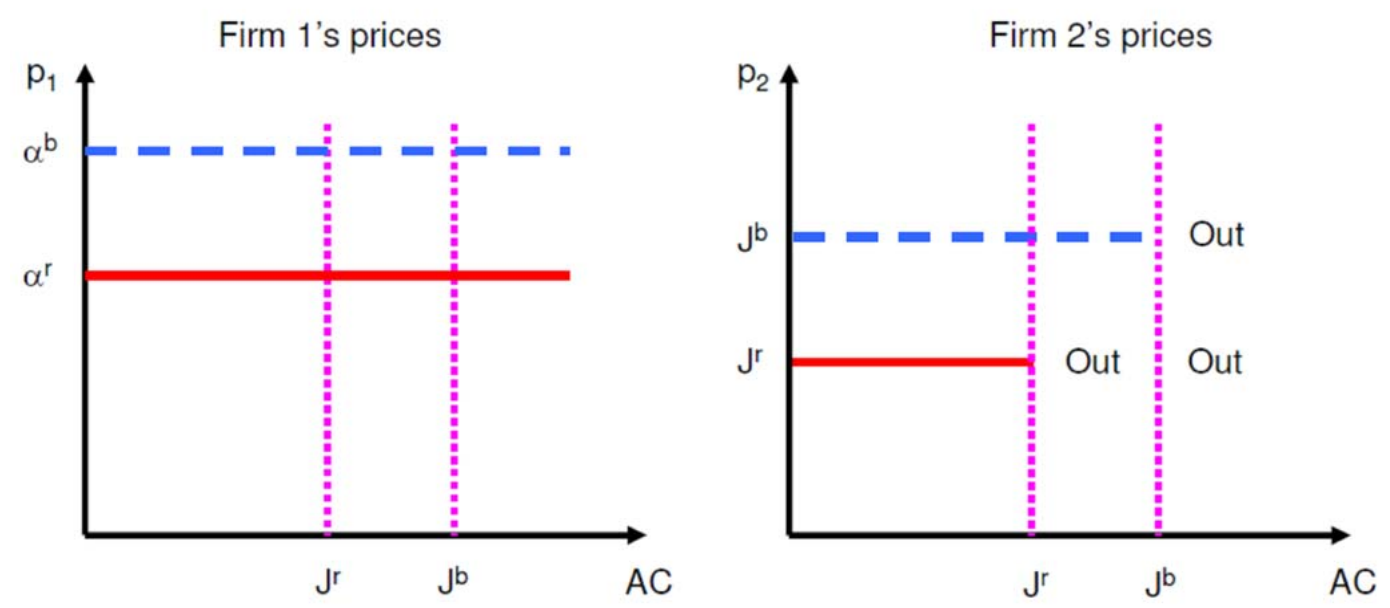

Figure 2: The equilibrium prices when firm 2 is a leader

As for price-cost margins, Proposition 4 implies that the industry Lerner index in state $i$ is given by

$$
L^{i}=\left\{\begin{array}{cc}
\frac{Q^{i}-k}{Q^{i}} \times \frac{\alpha^{i}-c}{\alpha^{i}}+\frac{k}{Q^{i}} \times \frac{J^{i}-c}{J^{i}} & A C \leq J^{i}, \\
1 \times \frac{\alpha^{i}-c}{\alpha^{i}} & A C>J^{i} .
\end{array}\right.
$$

Since $\alpha^{b}>\alpha^{r}, J^{b}>J^{r}$, and $Q^{b}>Q^{r}$, it is clear that $L^{b}>L^{r}$ when $A C \leq J^{r}$ and when $A C>J^{b}$. If we assume in addition that

$$
Q^{b}-k>\frac{\alpha^{r}-c}{\alpha^{b}-c}
$$

then

$$
\begin{aligned}
J^{b} \equiv c+\left(Q^{b}-k\right)\left(\alpha^{b}-c\right) & =\alpha^{r}+\left(Q^{b}-k\right)\left(\alpha^{b}-c\right)-\left(\alpha^{r}-c\right) \\
& =\alpha^{r}+\left(\alpha^{b}-c\right)\left[Q^{b}-k-\frac{\alpha^{r}-c}{\alpha^{b}-c}\right] \\
& >\alpha^{r}
\end{aligned}
$$


which implies that $\frac{J^{b}-c}{J^{b}}>\frac{\alpha^{r}-c}{\alpha^{r}}$. This ensures in turn that $L^{b}>L^{r}$ when $J^{r}<A C \leq J^{b}$. Hence, as in the case where firm 1 is the first mover, here (under the additional constraint (7)), we also get procyclical price-cost margins. ${ }^{12}$

Proposition 4 also implies that the procyclicality of profits is robust to the identity of the first mover. To see why, note that firm 1's profit in state $i$ is $\left(Q^{i}-k\right)\left(\alpha^{i}-c\right)$ when $A C \leq J^{r}$ and $Q^{i}(A C-c)$ when $A C>J^{b}$. Since $Q^{b}>Q^{r}$ and $\alpha^{b}>\alpha^{r}$, firm 1's profit is procyclical in both cases. When $J^{r}<A C \leq J^{b}$, firm 1's profit is $\left(Q^{b}-k\right)\left(\alpha^{b}-c\right)$ in booms and $Q^{r}\left(\alpha^{r}-c\right)$ in recessions. Noting that $Q^{r} \leq 1,(7)$ ensures that firm 1's profit is also procyclical in this case. Firm 2's profit is also procyclical since it is equal to $k\left(\alpha^{i}-A C\right)$ if $A C \leq J^{r}$, and if $J^{r}<A C \leq J^{b}$, firm 2 operates in the market and makes a positive profit only in booms.

Although Propositions 1 and 4 generate similar predictions regarding entry, sales quantities, prices, price-cost margins, and profits, there are at least two important differences between the case where firm 1 is the first mover and the opposite case where firm 2 is the first mover. First, Figures 1 and 2 show that when firm 2 is the first mover, the equilibrium prices are weakly lower for firm and strictly lower for firm 2. The reason is that when firm 2 is the first mover, it must set at low judo prices to induce firm 1 to accommodate it. By contrast, when firm 1 is the first mover, it accommodates entry by setting high monopoly prices. In this sense, we get a more competitive outcome when firm 2 is the first mover than when firm 1 is the first mover.

Second, the low judo price that firm 2 sets when it enters the market gives rise to price dispersion. This is in contrast to Proposition 1 where the two firms set the same price when they are both active in the market. To examine how the extent of price dispersion varies over the business cycle, let us measure price dispersion in state $i$ by the coefficient of variation of prices. ${ }^{13}$ To this end, note that the average price in state $i=b, r$ is

$$
\widehat{p}^{i}=\frac{Q^{i}-k}{Q^{i}} \alpha^{i}+\frac{k}{Q^{i}} J^{i}=\alpha^{i}-\frac{k\left(\alpha^{i}-J^{i}\right)}{Q^{i}}
$$

\footnotetext{
${ }^{12}$ It should be noted that combined, (1) and (7) require that $\frac{\alpha^{r}-k}{\alpha^{b}-k}<Q^{b}-k<1$. That is, the gap between $Q^{b}$ and $k$ is not too small and not too large.

${ }^{13}$ This is a common measure of price dispersion, see e.g., Table 1 in Baye, Morgan, and Scholten, (2006).
} 
and the variance of price in state $i=b, r$ is

$$
\operatorname{Var}\left(p^{i}\right)=\frac{Q^{i}-k}{Q^{i}}\left(\alpha^{i}-\widehat{p}^{i}\right)^{2}+\frac{k}{Q^{i}}\left(J^{i}-\widehat{p}^{i}\right)^{2}=\frac{Q^{i}-k}{Q^{i}} \times \frac{k}{Q^{i}} \times\left(\alpha^{i}-J^{i}\right)^{2},
$$

where $\frac{Q^{i}-k}{Q^{i}}$ is the market share of firm 1 and $\frac{k}{Q^{i}}$ the market share of firm 2 . Using these expressions, the coefficient of variation of prices in state $i=b, r$ is

$$
C V\left(p^{i}\right)=\frac{\sqrt{\operatorname{Var}\left(p^{i}\right)}}{\widehat{p}^{i}}=\frac{\sqrt{k\left(Q^{i}-k\right)}\left(\alpha^{i}-J^{i}\right)}{Q^{i} \alpha^{i}-k\left(\alpha^{i}-J^{i}\right)} .
$$

Noting that $\alpha^{b}-J^{b}=\left(\alpha^{b}-c\right)\left(1+k-Q^{b}\right)$ and $\alpha^{r}-J^{r}=\left(\alpha^{r}-c\right) \frac{k}{Q^{r}}$, and simplifying, yields

$$
C V\left(p^{b}\right)=\frac{\sqrt{\frac{Q^{b}}{k}-1}}{\frac{Q^{b}}{k} \frac{1}{1+k\left(1-\frac{Q^{b}}{k}\right)} \frac{\alpha^{b}}{\alpha^{b}-c}-1}, \quad C V\left(p^{r}\right)=\frac{\sqrt{\frac{Q^{r}}{k}-1}}{\left(\frac{Q^{r}}{k}\right)^{2} \frac{\alpha^{r}}{\alpha^{r}-c}-1} .
$$

It turns out that $C V\left(p^{b}\right)$ could be above or below $C V\left(p^{r}\right)$.

An interesting implication of Proposition 4 is that although both firms charge higher prices in booms than in recessions, the average price paid by consumers is not necessarily procyclical. To see this, consider the case where $J^{r}<A C \leq J^{b}$, so that firm 2 enters in booms, but stays out in recessions. Then the average price in booms is $\widehat{p}^{b}$. In recessions, firm 2 stays out of the market and firm 1 serves the entire market at a price $\alpha^{r}$. If (7) holds, then $J^{b}>\alpha^{r}$, which implies in turn that $\widehat{p}^{b}>\alpha^{r}$; hence, the average price is higher in booms than in recessions. However, if (7) fails, then $\alpha^{r}>\widehat{p}^{b}$ whenever

$$
\alpha^{r}>\alpha^{b}-k\left(\alpha^{b}-c\right)\left(\frac{1+k}{Q^{b}}-1\right) .
$$

Hence when (8) holds, the average price in booms is lower than in recessions. The reason for this counterintuitive possibility is a composition effect: although firm 1 charges higher prices in booms than in recessions, firm 2 enters the market only during booms, and its price is lower than firm 1's price. When firm 2's price, $J^{b}$, is sufficiently below firm 1's price in recessions, $\alpha^{r}$, the average price in booms will end up being below the average price in recessions. Notice that this case arises only when $\alpha^{r}$ is sufficiently close to $\alpha^{b}$. 
We report these results in the following proposition:

Proposition 5: When firm 2 is the first mover,

(i) there is price dispersion whenever firm 2 enters the market;

(ii) the extent of price dispersion can be pro- or counter-cyclical;

(iii) the average price during booms is below the average price during recessions if (8) holds.

Part (i) of Proposition 5 suggests that price dispersion can arise due to the low price that firm 2 sets in order to induce firm 1 to accommodate it. While this result replicates the familiar judo economics result, part (ii) of Proposition 5, which as far as we know is novel, shows that the extent of price dispersion varies over the business cycle and can either be pro- or countercyclical. Evidence for procyclical price dispersion is found Cornia, Gerardi, and Shapiro (2012). They examine the prices of domestic, direct, coach-class airline tickets in the U.S. over the period 1993 to 2009 and find that price dispersion is highly pro-cyclical, especially for legacy carriers and especially when concentration is high.

A number of papers have documented that retail prices for many products tend to fall during periods of peak demand (see e.g., Warner and Barsky (1995), MacDonald (2000), and Chevalier, Kashyap and Rossi (2003)). Part (iii) of Proposition 5 suggests that this phenomenon may be due to a composition effect: lower price firms increase their market shares when demand peaks, and this may lead to an overall decrease in average prices. Interestingly, Hatzitaskos and Nevo (2006) use the Chevalier, Kashyap and Rossi (2003) data and find support for the existence of a composition effect. ${ }^{14}$

\footnotetext{
${ }^{14}$ For insatnec, they find that when the demand for tuna peaks during Lent, much of the increase in sales is due to two relatively cheap products, whose market share is tripled despite the fact that their prices do not fall.
} 


\section{Concluding remarks}

We develop a simple model intended to explore the joint determination of prices, sales, and entry and examine how they vary over the business cycle. Our model is based on the idea that demand fluctuations affect the incentives of an incumbent firm to set low prices to keep a potential entrant out of the market. It predicts that prices, price-cost margins, and entry are all procyclical, but capacity utilization by the incumbent firm can be either pro- or countercyclical when the incumbent if the first mover and price dispersion can also be either pro- or countercyclical when the entrant is the first mover. Our model also shows that entry deterrence by the incumbent firm can either amplify or dampen the effect of demand fluctuations on prices, price-cost margins, and capacity utilization.

As mentioned in the Introduction, our paper belongs to the class of models in which the cyclical behavior of prices and price-cost margins (as well as entry and capacity utilization) is due to strategic interactions among firms. Most other papers in this class study the effect of demand fluctuations on the ability of firms to collude. The two most influential papers in this class are Green and Porter (1984) and Rotemberg and Saloner (1986). In Green and Porter (1984) collusion can be sustained in high demand states, but it completely breaks down in low demand states because firms cannot tell if their low sales are due to low demand, or due to a deviation from the collusive agreement by a rival. Hence like in our model, their model predicts procyclical prices and price-cost margins. By contrast, Rotemberg and Saloner (1986) predict countercyclical price-cost margins, which is the opposite of what our model predicts. In both models, symmetric firms are assumed to operate at unlimited capacity. At least the Rotemberg and Saloner result is clearly driven by this assumption. Also, unlike our paper, neither paper allows for entry and exit and hence these papers do not generate predictions regarding the joint determination of prices, price-cost margins, and entry.

Finally, the firms in our model have asymmetric capacities. Compte, Jenny and Rey (2003) show that asymmetric capacities hinder the ability of firms to collude if the aggregate capacity of all active firms is small relative to market size, but may facilitate collusion otherwise. 
To the extent that the market expands in booms and contracts in recessions, their results suggest that collusion should be harder to sustain in booms than in recessions. Contrary to our results, this would generate countercyclical price-cost margins.

\section{References}

Bagwell K. and R. Staiger (1997), "Collusion over the Business Cycle," RAND Journal of Economics, 28(1), 82-106.

Baye M., J. Morgan, and P. Scholten (2006), "Information, Search, and Price Dispersion," Chapter 6 in Handbook in Economics and Information Systems, Volume 1 (T. Hendershott, Ed.), Amsterdam: Elsevier.

Bils M. (1987), "The Cyclical Behavior of Marginal Cost and Price," The American Economic Review, 77(5), 838-855.

Bils M. (1989), "Pricing in a Customer Market," The Quarterly Journal of Economics, 104(4), 699-718

Campbell J. (1998), "Entry, Exit, Embodied Technology, and Business Cycles," Review of Economic Dynamics, 1(2), 371-408.

Chevalier J., A. Kashyap, and P. Rossi (2003), "Why Don’t Prices Rise During Periods of Peak Demand? Evidence from Scanner Data," American Economic Review, 93(1), 15-37.

Chevalier J. and D. Scharfstein (1996), "Capital-Market Imperfections and Countercyclical Markups: Theory and Evidence," The American Economic Review, 86(4), 703-725.

Cornia N., K. Gerardi, and A-H. Shapiro (2012), "Price Dispersion over the Business Cycle: Evidence from the Airline Industry," The Journal of Industrial Economics, 60(3), 347373.

Compte, O., F. Jenny, and P.Rey (2002), "Capacity Constraints, Merger, and Collusion," European Economic Review, 45, 1-29

Domowitz, I., G. Hubbard, and B. Petersen (1986a), "Business Cycles and the Rela- 
tionship between Concentration and Price-Cost Margins," The RAND Journal of Economics, 17(1), 1-17.

Domowitz, I., G. Hubbard, and B. Petersen (1986b), "The Intertemporal Stability of the Concentration-Margins Relationship," Journal of Industrial Economics, 35(4), 13-34.

Domowitz, I., G. Hubbard, and B. Petersen (1987), "Oligopoly Supergames: Some Empirical Evidence on Prices and Margins," The Journal of Industrial Economics, 35(4), 379-398.

Domowitz, I., G. Hubbard and B. Petersen (1988), "Market Structure and Cyclical Fluctuations in Manufacturing," The Review of Economics and Statistics, 70(1), 55-66.

Edmond C. and L. Veldkamp (2009), "Income Dispersion and Counter-Cyclical Markups," Journal of Monetary Economics, 56, 791-804.

Ellison, G. (1994), "Theories of Cartel Stability and the Joint Executive Committee," The RAND Journal of Economics, 25(1), 37-57.

Fabra, N. (2006), "Collusion with Capacity Constraints Over the Business Cycle," International Journal of Industrial Organization, 24(1), 69-81.

Galeotti, M. and F. Schiantarelli (1998), "The Cyclicality of Markups in a Model with Adjustment Costs: Econometric Evidence for US Industry," Oxford Bulletin of Economics and Statistics, 60, 121-142.

Gelman J.R. and S.C. Salop (1983), "Judo Economics: Capacity Limitation and Coupon Competition," Bell Journal of Economics, 14(2), 315-325.

Gerardi K, and A-H. Shapiro (2009), "Does Competition Reduce Price Dispersion? New Evidence from the Airline Industry," Journal of Political Economy, 117(1), 1-37.

Gottfries N. (1991), "Customer Markets, Credit Market Imperfections and Real Price Rigidity," Economica, 58, 317-323

Green E. and R. Porter (1984), "Noncooperative Collusion Under Imperfect Price Information," Econometrica, 52(1), 87-100.

Haltiwanger J. and J. Harrington (1991), "The Impact of Cyclical Demand Movements on Collusive Behavior," RAND Journal of Economics, 22(1), 89-106. 
Haskel J. and C. Martin (1994), "Capacity and Competition: Empirical Evidence on UK Panel Data," Journal of Industrial Economics, 42(1), 23-44.

Haskel J., C. Martin and I. Small (1995), "Prices, Margial Cost and the Business Cycle," Oxford Bulletin of Economcs and Statistics, 57(1), 25-41.

Hatzitaskos K.and A. Nevo (2006), "Why Does the Average Price Paid Fall During High Demand Periods?" Mimeo, Northwestern University.

Klemperer P. (1995), "Competition when Consumers have Switching Costs: An Overview with Applications to Industrial Organization, Macroeconomics, and International Trade," The Review of Economic Studies, 62(4), 515-539.

Lee Y. and T. Mukoyama (2013), "Entry, Exit, and Plant-level Dynamics over the Business Cycle," mimeo

MacDonald J. (2000), "Demand, Information and Competition: Why Do Food Prices Fall at Seasonal Demand Peaks?" Journal of Industrial Economics, 48(1), 27-45.

Machin S. and J. Van Reenen (1993), "Profit Margins and the Business Cycle: Evidence from UK Manufacturing Firms," Journal of Industrial Economics, 41(1), 29-50,.

Nekarda C. and V. Ramey (2013), "The Cyclical Behavior of the Price-Cost Markup," Mimeo

Oliveira Martins J, S. Scarpetta and D. Pilat (1996), "Mark-Up Pricing, Market Structure, and the Business Cycle," OECD Economic Studies, No . 27, 71-105.

Portier F. (1995), "Business Formation and Cyclical Markups in the French Business Cycle," Annals of Economics and Statistics, No. 37/38, 411-440.

Rotemberg J. and G. Saloner (1986), "A Supergame-Theoretic Model of Price Wars During Booms," American Economic Review, 76(3), 390-407.

Rotemberg J., and M. Woodford (1991), "Markups and the Business Cycle," NBER Macroeconomics Annual 1991, 6, 63-140.

Rotemberg, J. and M. Woodford (1999), "The cyclical behavior of prices and costs," in: Taylor J. B. and M. Woodford (ed.), Handbook of Macroeconomics, edition 1, volume 1, chapter 
16, pages 1051-1135, Elsevier.

Rosenbaum D. and S. Sukharomana (2001), "Oligopolistic Pricing Over the Deterministic Market Demand Cycle: Some Evidence from the US Portland Cement Industry," International Journal of Industrial Organization, 19(6), 863-884.

Staiger R. and F. Wolak (1992), "Collusive Pricing with Capacity Constraints in the Presence of Demand Uncertainty," Rand Journal of Economics, 23(2), 203-220.

Warner E. and R. Barsky (1995), "The Timing and Magnitude of Retail Store Markdowns: Evidence from Weekends and Holidays," Quarterly Journal of Economics, 110(2), 321352.

Wilson B. and S. Reynolds (2005), "Market Power and Price Movements over the Business Cycle," Journal of Industrial Economics, 53(2), 145-174. 